\title{
The Effects of Hippotherapy for Physical, Cognitive and Psychological Factors in Children with Intellectual Disabilities
}

\author{
Myung-Soo Bae $\cdot$ Chang-Kyo Yun ${ }^{1 \dagger} \cdot$ Yong-Gu Han ${ }^{\dagger}$ \\ Dept. of Therapeutic riding \& Welfare, Sungduck University \\ ${ }^{1}$ Dept. of Physical Therapy, Daegu University Rehabilitation Medical Clinic
}

Received: July 26, 2017 / Revised: July 27, 2017 / Accepted: August 7, 2017

(c) 2017 J Korean Soc Phys Med

\begin{abstract}
| Abstract |
PURPOSE: The purpose of this study is to determine, by conducting a 10 week hippotherapy, the effects on the physical, cognitive and psychological factors of children with intellectual disabilities.
\end{abstract}

METHODS: As an intervention method, intervention was based on a program from the American Hippotherapy Association and was modified and enhanced. 16 children with intellectual disabilities was conducted horse riding intervention program and Intervention was conducted once a week for a total of 10 weeks with each session lasting 30 minutes. A doctor of rehabilitation medical treatment of $\mathrm{D}$ rehabilitation center, physical therapist and occupational therapist evaluated the upper limbs test, balance, gait function, Korea-mini mental state examination (MMSE) before and after hippotherapy intervention. Self-esteem scale and aggression scale was evaluated by Psychology Counseling of $\mathrm{C}$ psychological clinic before and after hippotherapy intervention.

$\dagger$ Corresponding Author: puhaha1116@naver.com This is an Open Access article distributed under the terms of the Creative Commons Attribution Non-Commercial License (http://creativecommons.org/licenses/by-nc/3.0) which permits unrestricted non-commercial use, distribution, and reproduction in any medium, provided the original work is properly cited.
RESULTS: The results of this study reveal that first, there was a positive effect. Second, statistically significant differences were found in BBS, TUG, K-MMSE, 10m walking test, 6 min walking test, self-esteem scale and aggression scale $(p<.05)$. However no statistically significant differences were found in upper limbs function and good balance analysis before and after intervention.

CONCLUSION: The hippotherapy is effective way to improve the physical, cognitive and psychological factors of children with intellectual disability.

Key Words: Cognition, Hippotherapy, Intellectual disabilites, Psychology

\section{Introduction}

Regarding the terminology for cognitive developmental disability, mental deficiency was used in the 1950s, but intellectual disability is used now to improve negative perceptions associated with the disorder (Schalock et al., 2007). Children with intellectual disabilities are those who have the onset of intellectual disability before the age 18 of, score 70 or lower on a validated standardized intelligence test, and show deficits or severe limitations in two or more areas of adaptability, such as communication, self-care, 
family life, social relations, occupation, leisure, health, and safety (Schalock et al., 2007).

In fact, children with intellectual disabilities tend to exhibit a higher level of depression and displaced aggression expressed towards innocent targets compared to their counterparts (Wehmeyer and Schwartz, 1997; Choi, 2002). In addition, their overall behavior, including walking speed, tends to be slow, despite their developmental process being normal, because they score low on strength, balance, and agility (Francis and Rarick, 1962). moreover, their muscle strength, cardiopulmonary endurance, and adaptability according to changes in location, sense of orientation, and position are lower than those of their counterparts (Ro, 2008).

In recent years, in order to solve this problem, intervention with physical activity for children with intellectual disabilities has drawn attention. Yoon and Park (2013) reported that the increase in physical activity had a positive effect on perceptions and cognitive development in children with intellectual disabilities, and that the increase in physical experience promoted intellectual, emotional, and social development in the children. In addition, ongoing program participation is an important aspect of intervention for children with intellectual disabilities because those who participate in ongoing training and education show a higher level of daily functioning than those who do not (Drew and Hardman, 2004). However, since children with intellectual disabilities lack the willingness to participate in exercise, and their disabilities make it difficult to carry out physical activity, interventions that utilize interaction with animals have gained increasing attention in recent years (O'Haire, 2013).

Animal-assisted therapy refers to deliberately planned, educational, and socially integrated interventions that use animals with a group of children, adolescents, adults, or the elderly with cognitive, affective, and motor skills disabilities and behavioral problems (Fine, 2010). It has been demonstrated that animal-assisted therapy is more accommodating than static-mode indoor therapies (Seo,
2012) and is effective in enhancing self-esteem in children (Heo and Hong, 2013). It has also been reported that animal-assisted therapy enhances the ability to recover from disease, reduces depression and sense of loneliness, and maintains social support in the elderly, suggesting its physical and psychological effects (Kim and Youn, 2014). Therefore, animal-assisted therapy is widely used as an effective intervention. In recent years, interventions using horses have drawn attention in conjunction with government programs for development of the equine industry (Hession et al., 2014).

Hippotherapy is defined as "equine-assisted therapy" for patients with physical and cognitive disabilities (Anesti et al., 2014). It has a wide range of applications and intended populations, and experts in various fields have tried to demonstrate its efficacy (Hession et al., 2014; Anesti et al., 2014; Seo, 2012). In terms of outcomes reported by previous studies, Kwon et al. (2015) found that hippotherapy improved gross motor function in children with cerebral palsy, and Lee and Jeong (2005) reported that indoor horseback riding exercise was effective in improving stamina, blood lipid concentration, and bowel satisfaction. It has also been reported that improved physical activity has a positive effect on social maturity in children with intellectual disabilities (Kim, 2007), and that the horseback riding program moderates hyperactivity in autistic children (Gabriels et al., 2012). These findings suggest that improved physical activity with hippotherapy has positive effects on physical abilities and psychological functioning in various populations.

As a type of animal-assisted therapy, therapeutic horseback riding has been found to be effective in enhancing physical ability in various populations, such as those with cerebral palsy. However, research on horseback riding in children with intellectual disabilities is extremely lacking, as is research analyzing the physical, cognitive, and psychological aspects simultaneously. The present study investigates the effects of horseback riding on psychological 
aspects, including self-esteem and aggression, cognitive aspects measured by the Mini-Mental State Exam (MMSE), and physical aspects measured by balance test, gross motor function measure, gait test, and upper limbs test.

\section{Methods}

\section{Subjects}

In the study, a hippotherapy program was implemented with 16 children with intellectual disabilities with support from the Yeongcheon Office of Education Support of Gyeongbuk province. The program subjects were randomly selected from elementary, middle school, and high school students in special education classes who had participated in the public horseback riding experiential program for students and had applied for the hippotherapy program. The study was conducted between April 1 and November 30, 2016. Specifically, after developing a horse training guide for hippotherapy to fit the research objectives, and training four horses (one pony, one Halla breed horse, and two thoroughbreds) for the experiment according to the guide between April 1 and August 30, a weekly hippotherapy program was implemented from September 1 to November 30. Study subjects had been medically diagnosed with mental retardation and intellectual disability, and were randomly assigned to one of the four trained horses.

\section{The general characteristic of subjects}

Before the participation of the study, every subjects had to listen to a purpose and a process of the study with full details and they spontaneously signed up on the agreement of the study, they also participated after parents of the subjects and their school officials agreed with that participation.

Common characteristics of subjects are as follows (Table 1).

1) Subjects with medical diagnosis of intellectual disability

2) Subjects who can sit on their own

3) Subjects who are capable of opening hip joints sufficiently for maintaining the sitting posture on the horse

4) Subjects who are not at safety risk such as epilepsy

The upper limbs test, the cognitive function test, and psychological assessments were used in this study to assess the subjects. The upper limbs test and the cognitive function tests were conducted before and after the hippotherapy program for each group of subjects with the assistance of a rehabilitation medicine specialist, an occupational therapist, and a physical therapist from Rehabilitation Center D in Daegu. Psychological assessments of aggression and self-esteem were conducted before and after the program for each group of subjects by counseling specialists in Counseling Center $\mathrm{C}$ in Jeonbuk. Items other than self-esteem and aggression were assessed for 10 subjects only owing to compromised attention levels and other cognitive difficulties during measurement.

\section{Implementation of the Hippotherapy Program}

The program was developed by adapting a hippotherapy program developed in American Hippotherapy Association (2010) to the Korean context. Implementation of the progra

Table 1. The general characteristic of subjects

$(\mathrm{N}=16)$

\begin{tabular}{lcccc}
\hline Characteristic & Minimum value & Maximum value & Mean & SD \\
\hline Age $(\mathrm{yrs})$ & 11.5 & 15 & 13.68 & 1.75 \\
Height $(\mathrm{cm})$ & 133 & 163 & 152.18 & 10.03 \\
Weight $(\mathrm{kg})$ & 27 & 58 & 49.43 & 8.49 \\
\hline
\end{tabular}

SD: standard deviation 
Table 2. 1th $\sim$ 10th Week horse riding intervention program

\begin{tabular}{|c|c|c|}
\hline Session & Program & \\
\hline \multirow{3}{*}{$1 \sim 10$} & Preparation & $\begin{array}{l}\text { - Prepare horse riding clothes by himself } \\
\text { - Stroke the horse back } \\
\text {. Call the name of the horse }\end{array}$ \\
\hline & Horse back riding & $\begin{array}{l}\text { Position : Position : Sitting } \rightarrow \text { Reverse, Sitting } \rightarrow \text { Sitting } \\
\text { - Tool : Poles, Stick, Cones, Ball } \\
\text { Time : } 15-20 \text { min } \\
\text { - Gait of horse : Walk, A little fast walk, Fast walk } \\
\text { - Skill : Sustain balance at fast walk, Upper limbs training by using various tools }\end{array}$ \\
\hline & Finishing & $\begin{array}{l}\text { - Stroke the horse back } \\
\text { - Stop the horse } \\
\text { - Descend from the horse }\end{array}$ \\
\hline
\end{tabular}

$\mathrm{m}$ was tailored to the physical conditions of individual subjects. The outline of the program is shown in the table below (Table 2).

1) Program time : 20 30 minute

2) Tools : poles, Stick, cones, Ball

\section{Measurement tools}

\section{1) Physical function}

(1) Balance

(1) Berg balance scale (BBS)

The Berg Balance Scale (BBS) was developed by Kathy Berg, a Canadian physical therapist. The scale has 14 items on five-point scales ( $0 \sim 4$ points) with a maximum possible total of 56 points. Higher scores indicate greater balance. The scale is a highly reliable measure with inter-rater reliability of $r=.98$ and intra-rater reliability of $r=.99$ (Bogl and Newton, 1996).

\section{(2) Timed up and go test (TUG)}

The Timed up and Go test (TUG) is tool for assessing functional mobility and dynamic balance. Each subject is instructed to sit on a chair with arm rests, then stand up at the tester's signal, walk 3 meters at a comfortable pace, come back, and sit on the chair. Each subject completes the sequence three times, and the amount of time required for each sequence is measured and the average of the three is recorded. This is also a highly reliable measure with inter-rater reliability of $r=.98$ and intra-rater reliability of $\mathrm{r}=.99$ (Podsiadlo and Richardson, 1991).

\section{(3) Good balance}

The study also used Good balance (Good balance, AP1135, Finland), which was developed to evaluate the balance of neurologically impaired patients. Subjects are instructed to step on a plate and then make forward and backward movements and movements to the left and the right without holding a handle with their eyes open and closed. The speeds of the movements are then measured.

(2) Gait function

(1) 10 meter walking test

The 10 meter walking test involves measuring a 10 meter walk within a 14 meter walk distance by marking the 3 meter and the 12 meter points to start and end the measurement. The test demonstrates high reliability with intraclass correlation of $.95-.96$ for test-retest reliability (Fulk and Echternach, 2008).

(2) 6 minute walking test

The 6 minute walk test was also conducted by measuring the distance that each subject walks for 6 minutes from a start point marked on the ground at the test administrator's 
instruction. The test is conducted three times for each subject and the average of the three recorded. The test is suitable for measuring the gait and endurance of neurologically impaired patients. The test demonstrates high reliability with ICC (Intraclass correlation coefficient) $\mathrm{r}=.94$ for test-retest reliability (Mossberg et al., 2003).

(3) Gross motor function measure (GMFM)

The Gross motor function measure (GMFM) is a highly reliable assessment tool for motor skills of children with neurological disorders. The measure assesses motor development with 88 items in five domains. The test demonstrates high reliability (Lee and Kim, 2015).

(4) Upper limbs test

The upper limbs test is conducted using Winarm software (Winarm software, Zebris Medical $\mathrm{GmbH}$, Germany), which is capable of measuring movements. The test involves measuring the positions of arm joints at $30^{\circ}$ and $110^{\circ}$ using a goniometer, and then starting measuring again at $110^{\circ}$ and $30^{\circ}$ as the subject lowers his or her arm. The sequence is repeated 10 times. For precise measurement, two test administrators took measurements according to the instrument manual.

\section{2) Korea-mini mental state examination (K-MMSE)}

The MMSE is a quick assessment tool for various cognitive functions with demonstrated reliability and validity. MMSE consists of seven domains and is highly reliable $(r=.99)$ for assessing children's cognitive function (Yoon et al., 2016).

\section{3) Psychological Factor}

(1) Self-Esteem Scale (SES)

The self-esteem of the subjects was assessed using Jeon (1974) questionnaire. The questionnaire has 10 items including five positively-scored and five negatively-scored items on a five-point scale (1-5 points), with a reliability of $r=.68$ (Cronbach' $a$ ). The test is organized as follows (Table 3).

\section{(2) Aggression scale}

The aggression scale used in the study consists of 21 items in five areas - physical aggression, hostility, verbal aggression, suspicion, and anger. Higher scores indicate higher levels of aggression. The alphas were as follow $r=.89$ (Buss and Perry, 1992). The subscale items are listed as follows (Table 4).

Table 3. Self-esteem scale

\begin{tabular}{llcc}
\hline Variable & Item number & Number of questions & Cronbach' $\alpha$ \\
\hline Positive self-esteem & $1,2,4,6,7$ & 5 & \\
Negative self-esteem & $3,5,8,9,10$ & 5 & .68 \\
\hline Total & & 10 & \\
\hline
\end{tabular}

Table 4. Aggression scale

\begin{tabular}{llcc}
\hline Variable & Item number & Number of questions & Cronbach' $\alpha$ \\
\hline Physical aggression & $1,2,3,5,6,7$ & 6 & \\
Enemy & $14,15,16,18,20$ & 5 & \\
Linguistic attack suspicion & $9,10,11,13,19,21$ & 6 & \\
Anger & $4,8,12,17$ & 4 & .70 \\
\hline Total & & 21 & \\
\hline
\end{tabular}


5. Data analysis

SPSS/PC ver.22 was used to analysis data. Pared t-test was used in order to examine change of aggression scale, self-esteem scale and K-MMSE. Shapiro-wilk test used to verify the significance of pre-testing and post-testing. Eye open velocity movement, Eye closed speed movement anterior/posterior and medial/lateral, Eye open velocity movement at Good balance that satisfied with test of normality were carried out using pared t-test. Eye open speed movement anterior/posterior and medial/lateral at good balance, BBS, TUG, 10mwt, 6minwt, Upper limbs test and GMFM that not satisfied with test of normality were carried out using Wilcoxon's signed-ranks test. Findings were considered statistically significant at $\mathrm{p}<.05$.

\section{Results}

\section{Balance analysis}

When analyzing TUG, BBS, Good balance before and after intervention, it was found that there were significant differences in TUG, BBS as shown in $(\mathrm{p}<.05)$ (Table 5). No statistically significant differences were founded in Good balance. However, it was found that there were differences in eye open mean speed movement Anterior/ Posterior and Medial/Lateral, eye open velocity movement, eye closed mean speed movement Anterior/Posterior and eye closed velocity movement in numbers (Table 6, 7).

Table 5. Changes pre-post in TUG and BBS following hippotherapy

\begin{tabular}{llllll}
\hline & Pre & Post & \multirow{2}{*}{ z } & $\mathrm{p}$ \\
\cline { 2 - 4 } & mean \pm SD & mean \pm SD & -2.02 & .04 \\
\hline TUG & $7.82 \pm .57$ & $6.95 \pm .47^{*}$ & -2.03 & .04 \\
\hline
\end{tabular}

TUG: timed up and go test, BBS: berg balance scale, ${ }^{*} \mathrm{P}<.05$

Table 6. Changes in good balance Eyes open following hippotherapy

\begin{tabular}{llllll}
\hline & Pre & Post & \multirow{2}{*}{ z } & $\mathrm{p}$ \\
\cline { 2 - 3 } & mean \pm SD & mean \pm SD & & .1 .17 & .24 \\
\hline EO mean speed movement AP & $6.06 \pm 3.81$ & $7.45 \pm 3.96$ & -.96 & .33 \\
EO mean speed movement ML & $7.99 \pm 3.83$ & $9.30 \pm 5.86$ & $35.09 \pm 40.08$ & -.25 & .80 \\
\hline
\end{tabular}

EO: Eye open

Table 7. Changes good balance Eyes closed and Eye open velocity movement following hippotherapy

$(\mathrm{N}=10)$

\begin{tabular}{llllll}
\hline & Pre & Post & \multirow{2}{*}{$\mathrm{p}$} & \\
\cline { 2 - 3 } & mean \pm SD & mean \pm SD & & .80 \\
EO velocity movement & $32.33 \pm 45.66$ & $35.09 \pm 40.08$ & & .25 \\
EC mean speed movement AP & $9.22 \pm 10.06$ & $9.94 \pm 11.43$ & -.91 & .38 \\
EC mean speed movement ML & $11.70 \pm 9.53$ & $11.17 \pm 8.25$ & .23 & .82 \\
EC velocity movement & $58.37 \pm 91.93$ & $75.85 \pm 136.12$ & -1.22 & -1.22 \\
\hline
\end{tabular}

EO: Eye open, EC: Eye closed 
Table 8. Changes pre-post in many subjects following hippotherapy

\begin{tabular}{lllll}
\hline & Pre & Post & $\mathrm{z}$ & $\mathrm{p}$ \\
\cline { 2 - 4 } & mean $\pm \mathrm{SD}$ & mean $\pm \mathrm{SD}$ & -2.02 & .04 \\
\hline 10 meter walking test & $11.32 \pm 2.49$ & $9.81 \pm 1.75^{*}$ & -2.02 & .04 \\
6 minute walking test & $368 \pm 74.13$ & $425.00 \pm 67.87^{*}$ & -2.02 & .04 \\
GMFM & $205.80 \pm 17.48$ & $250.20 \pm 11.12^{*}$ & -.86 & .38 \\
Upper limbs test & $3.92 \pm 1.9$ & $3.3 \pm 1.4$ & -2.03 & .04 \\
K-MMSE & $16.80 \pm 8.11$ & $19.6 \pm 6.43^{*}$ & & \\
\hline
\end{tabular}

GMFM: gross motor function measure, K-MMSE: Korea-mini mental state examination

* 10 meter walking test, 6 minute walking test, GMFM, K-MMSE: $\mathrm{P}<.05$

Table 9. Changes pre-post in self-esteem scale following hippotherapy

\begin{tabular}{|c|c|c|c|c|c|c|}
\hline Variable & & & & SD & $\mathrm{t}$ & $\mathrm{p}$ \\
\hline \multirow{6}{*}{ Self-esteem } & \multirow{2}{*}{$\begin{array}{l}\text { Positive } \\
\text { self-esteem }\end{array}$} & Pre & 16.00 & 4.42 & \multirow{2}{*}{-3.06} & \multirow{2}{*}{$.00 *$} \\
\hline & & Post & 19.06 & 4.44 & & \\
\hline & \multirow{2}{*}{$\begin{array}{l}\text { Negative } \\
\text { self-esteem }\end{array}$} & Pre & 15.06 & 3.19 & \multirow{2}{*}{-4.23} & \multirow{2}{*}{$.00 *$} \\
\hline & & Post & 18.63 & 2.80 & & \\
\hline & \multirow{2}{*}{ Total } & Pre & 31.06 & 5.61 & \multirow{2}{*}{-5.53} & \multirow{2}{*}{$.00^{*}$} \\
\hline & & Post & 37.69 & 6.21 & & \\
\hline
\end{tabular}

$* \mathrm{P}<.01$

Table 10. Changes pre-post in Aggression following hippotherapy

\begin{tabular}{|c|c|c|c|c|c|c|}
\hline \multicolumn{3}{|c|}{ Variable } & Mean & $\mathrm{SD}$ & $\mathrm{t}$ & $\mathrm{p}$ \\
\hline \multirow{10}{*}{$\begin{array}{l}\text { Intrinsic } \\
\text { Motivation }\end{array}$} & \multirow{2}{*}{ Physical Aggression } & Pre & 19.56 & 3.01 & \multirow{2}{*}{6.28} & \multirow{2}{*}{$.00 *$} \\
\hline & & Post & 15.00 & 3.01 & & \\
\hline & \multirow{2}{*}{ Enemy } & Pre & 14.56 & 5.12 & \multirow{2}{*}{4.81} & \multirow{2}{*}{$.00 *$} \\
\hline & & Post & 9.50 & 3.84 & & \\
\hline & \multirow{2}{*}{$\begin{array}{l}\text { Linguistic Attack · } \\
\text { Suspicion }\end{array}$} & Pre & 19.38 & 4.71 & \multirow{2}{*}{5.00} & \multirow{2}{*}{$.00 *$} \\
\hline & & Post & 13.38 & 3.86 & & \\
\hline & \multirow{2}{*}{ Anger } & Pre & 15.06 & 1.69 & \multirow{2}{*}{4.54} & \multirow{2}{*}{$.00 *$} \\
\hline & & Post & 11.81 & 3.06 & & \\
\hline & \multirow{2}{*}{ Total } & Pre & 68.56 & 11.21 & \multirow{2}{*}{7.42} & \multirow{2}{*}{$.00 *$} \\
\hline & & Post & 50.13 & 7.82 & & \\
\hline
\end{tabular}

$* \mathrm{P}<.01$

2. Gait function, GMFM, Upper limbs test, K-MMSE analysis

When analyzing $10 \mathrm{mwt}$ (10 meter walking test), 6minwt (6 minute walking test), Upper limbs test and K-MMSE before and after intervention, it was found that there were statistically differences in 10mwt, 6minwt and K-MMSE. No a statistically significant difference was founded in the Upper limbs test, but improved in numbers as shown in (Table 8).

\section{Psychological factor analysis}

Self-esteem scale and Aggression scale were significantly differences before and after intervention. In Self-esteem scale, both positive and negative self-esteem scale had statistically significant improvements as shown in (Table 9) $(\mathrm{p}<.05)$. In Aggression scale, There were statistically significant reduction in the physical aggression, Enemy, Linguistic attack suspicion and Anger as shown in $($ Table 10) $(\mathrm{p}<.05)$. 


\section{Discussion}

The present study was conducted according to "the Assessment Manual for Hippotherapy" which was developed by the National Institute of Animal Science of Korea to investigate the effects of a rehabilitation program that utilizes horseback riding on physical, cognitive, and psychological function in children with intellectual disabilities.

According to American Psychiatric Association (2013), infants who exhibit psychological and behavioral problems show serious disabilities in the development process, and functional deficits in developmental disabilities include both quantitative and qualitative aspects (Lee, 2007). Among the children with developmental disabilities, children with intellectual disabilities have disabilities in physical, academic, and psychological aspects (Choi, 2002; Francis and Rarick, 1962), and a variety of interventions are used to improve physical and cognitive impairments. In particular, recent studies highlight the importance of purposeful physical activities (Lee, 2007; Choi, 2002; Francis and Rarick, 1962).

Kang (2016)'s study found that increased physical activity enhanced adaptability in interaction with others, and increased self-confidence, independent behavior, and self-expression in children with intellectual disabilities. Lee (2007)'s study also reported that afterschool physical activity resulted in weight loss, and decrease in body mass index, body fat mass, body fat percentage, abdominal obesity rate, and visceral fat mass in children with intellectual disabilities. Research suggests the importance of increased physical activity in children with intellectual disabilities. Recent research trends show that a leading intervention focused on purposeful activity utilizes horseback riding (Hession et al., 2014; Lee et al., 2014; Baek and Kim, 2014).

According to American Hippotherapy Association (2010), "Equine-assisted therapy is not either psychological or physical therapy but both therapies," which suggests that programs that utilize horseback riding are used for psychological aspects, such as cognition, in addition to physical aspects. In particular, regarding research on psychological aspects, Chen et al. (2016) reported that the mental health of patients with spinal cord injuries improved after participation in therapeutic hippotherapy, and Song (2008) reported improved patience, self-confidence, emotional stability, self-management, and interpersonal relationships in special education students after participation in a program involving horseback riding. This is because interacting with a large animal helps subjects to experience the dignity of human life and a sense of accomplishment, and the unconditional acceptance offered by animals toward subjects enhances their interpersonal relationships (Karol, 2007), which ultimately has therapeutic effects on psychological aspects. In line with previous studies showing that hippotherapy is an effective intervention in improving psychological functioning in program subjects, the present study found a statistically significant reduction in aggression in children with intellectual disabilities after participating in hippotherapy. This result is consistent with studies conducted with other populations, and is thought that hippotherapy is effective intervention for improving the self-esteem scale and reducing aggression by providing an opportunity to enhance a sense of psychological stability and taking some time for self-examination in children with intellectual disabilities.

Moreover, MMSE, which is a measure of cognitive functioning, also showed a statistically significant improvement. The repeated motion in hippotherapy induces continuous sensory stimuli in subjects to create cognitive responses (Macauley, 2003), and provides learning effects such as sensory integration, movement planning, discrimination of the left and the right, and spatial senses (Jang et al., 2016). In studies conducted with other populations, it has been reported that cognitive functioning in children with dyspraxia improved after participation in hippotherapy (Hession et al., 2014), and Jang (2016) demonstrated that 
hippotherapy improved visual perception in children with cerebral palsy. By using various tools during horse riding intervention, it would have had a positive influence on the perception of the visual and cognitive learning. Therefore the present study conducted with children with intellectual disabilities produced similar results.

In terms of physical functioning, the TUG and BBS results showed improved balance in study subjects. In horseback riding, when the horse moves, the rider activates muscles in the body to reduce movement of the body and keep the centerline of the body (Shurtleff et al., 2009). As a result of this phenomenon, it was found that horseback riding led to a statistically significant improvement measured by BBS in stroke patients (Lee et al., 2014), and that 24 sessions of hippotherapy led to statistically significant improvement in the balance in the sitting position and dynamic balance in children with cerebral palsy (Moraes et al., 2016). This results are thought that hippotherapy led to similar improvements at the statistically significant level in the BBS and TUG tests in the present study conducted with children with intellectual disabilities by adjusting anticipatory postural control and reactive postural control to maintain the alignment of the body on a horse. The gait test also showed a similar improvement. Previous research on the association between horseback riding and walking has shown that horseback riding improved the walking speed and distance of palsy patients (Kwon et al., 2015), and similar results were found in stroke patients who participated in hippotherapy (Lee et al., 2014). Horseback riding induces pelvic movement similar to the normal gait pattern in the human body, and Facilitation of the movement also has a positive effect on walking on the ground (Kim et al., 2008). Therefore, it can be concluded that hippotherapy is an effective intervention for improving walking ability in various populations, and the present study also showed an improvement in children with intellectual disabilities. The GMFM results also showed a statistically significant improvement. Horseback riding reduces the abnormal stiffness of the muscles and increases stability of the trunk (Hong et al., 2016). Normality in the tone of muscles and stability of the trunk are vital to improvement of gross motor function, and the association between hippotherapy and gross motor function has been demonstrated in experiments with various populations. Kwon (2015)'s study showed that horseback riding improved gross motor function in children with cerebral palsy, and Im and Huh (2013) study showed that hippotherapy led to a statistically significant improvement in gross motor function and balance in children with brain lesions. Champagne and Dugas (2010) also reported that hippotherapy enhanced stability, gross motor function, and control of the head and the trunk. Thus, in this study, the improvement of the stability of the body through hippotherapy was thought that it has had a positive effect on enhancing GMFM in children with intellectual disabilities. However, the mean scores of the gait balance test and the arm function test showed no statistically significant improvement, whereas some items of the tests showed improvements in numbers. These results may suggest that despite the therapeutic effect of hippotherapy on physical ability in the children with intellectual disabilities, the current program did not deliver sufficient stimulus to make a statistically significant difference in the measurement areas because the intervention was carried out only once a week. Regarding gait balance and arm function, further research is warranted to test the efficacy of hippotherapy with increased session frequency.

The limitations of this study are as follows: First, the study presents the short-term effects of hippotherapy. Therefore, long-term effects of the intervention are unknown. Second, extraneous variables have not been controlled completely. The control was particularly difficult for some subjects who also participated in other therapeutic programs during the study period. Third, many subjects had difficulties in comprehending the questions on the questionnaire. It is suggested that future studies need to 
modify questionnaires considering the subject ages and cognitive levels. Fourth, disability class, age, and gender were not controlled completely. Thus, their effects on outcomes cannot be ruled out. Fifth, owing to the absence of a control group, the program's effects could not be determined in comparison with a no-intervention group or other intervention groups. Future studies that address these limitations are expected to be more effective and clinically applicable.

\section{Conclusion}

This study was performed to identify the effects of 10 week hippotherapy program on physical, cognitive, and psychological function in children with intellectual disabilities. The program was found to be effective in improving physical abilities, including balance, gait and gross motor function, cognitive function measured by MMSE, and psychological function measured using the self-esteem and the aggression scales. Thus, this study emphasizes a positive effect of a therapeutic horseback riding for children with intellectual disabilities and the focus of this study is on attracting people's attention to horseback riding and expanding the base of horse riding industry. Also, it is suggested that that hippotherapy is expected to be useful in providing effective interventions and it can be used in an alternative intervention for children with intellectual disabilities in the local community.

\section{Acknowledgements}

The study was conducted with support of Rural Development Administration (National Institute of Animal Science) in 2016.

\section{References}

American Hippotherapy Association. Hippotherapy as a treatment strategy. USA. American Hippotherapy Association. 2010.

American Psychiatric Association. Diagnostic and statistical manual of mental disorders (DSM-5th ed). USA. American Psychiatric Pub. 2013.

Anesti MD, Anestis JC, Zawilinski LL, et al. Equinerelated treatments for mental disorders lack empirical support: A systematic review of empirical investigations. J Clin Psychol. 2014;70(12):1115-32.

Baek IH, Kim, BJ. The effects of horse riding simulation training on stroke patients' balance ability and abdominal muscle thickness changes. J Phys Ther Sci. 2014;26(8):1293-6.

Bogl TLD, Newton RA. Use of the Berg Balance Test to predict falls in elderly persons. Phys Ther. 1996; 76(6):576-85.

Buss AH, Perry M. The aggression questionnaire. Journal of personality and social psychology. 1992;63(3):452.

Champagne D, Dugas C. Improving gross motor function and postural control with hippotherapy in children with Down syndrome. Physiother Theory Pract. 2010; 26(8):564-71.

Chen SY, Kim SK, Kim KH, et al. Effects of Horse Riding Simulator on Pain, Oswestry Disability Index and Balance in Adults with Nonspecific Chronic Low Back Pain. J Korean Soc Phys Med. 2016:11(4);79-84.

Choi $\mathrm{CH}$. Effects of social play programs on improvement of social skills of mentally retarded children. Master's Degree. Cheongju National University. 2002.

Drew CJ, Hardman ML. Mental retardation: A lifespan approach to people with intellectual disabilities. USA. Prentice Hall. 2004

Fine AH. Handbook on animal-assisted therapy: Theoretical foundations and guidelines for practice. USA. Academic Press. 2010. 
Francis RJ, Rarick GL. Motor characteristics of the mentally retarded. Am J Ment Defic. 1962;63(5):792-811.

Fulk GD, Echternach JL. Test-retest reliability and minimal detectable change of gait speed in individuals undergoing rehabilitation after stroke. J Neurol Phys Ther. 2008;32(1):8-13.

Gabriels RL, Agnew JA, Holt KD, et al. Pilot study measuring the effects of therapeutic horseback riding on school-age children and adolescents with autism spectrum disorders. Res Autism Spectr Disord. 2012;6(2):578-88.

Heo SY, Hong HJ. A Study about the effect of reading enhancement and the self respect Improvement of children through an animal assisted therapy. Journal of the Korean Biblia Society for Library and Information Science. 2013;24(3):181-98.

Hession CE, Eastwood B, Watterson D, et al. Therapeutic horse riding improves cognition, mood arousal, and ambulation in children with dyspraxia. J Altern Complement Med. 2014;20(1):19-23.

Hong CY, Jung NJ, Na SS, et al. Horse Riding Simulator Affect the Posture Alignment of Young Adults with Forward Head Posture. J Korean Soc Phys Med. 2016;11(4):19-26.

Im JH, Huh JH. An Investigation of the effects of rehabilitation horse riding on the gross motor function and muscle balance of mentally disabled children. KJSS. 2013;22(3):683-94.

Jang YS, Jeong GU, Kim H D, et al. A Literature Review on Effect of Theratainment Animal-assisted Therapy: For the Horseback Riding. KOEN. 2016;10(1):259.

Jeon BJ. Self-Esteem: A test of its measurability. Yonsei University. 1974;11:107-24.

Kang HM. A study on the change process of social behavior and interaction in physical activity of youth with intellectual disabled. KAHPERD. 2016;55(4):45-58.

Karol J. Applying a traditional individual psychotherapy model to equine-facilitated psychotherapy (EFP): Theory and method. Clin Child Psychol Psychiatry, 2007;12(1):77-90

Kim DH, Kim SJ, Bae SS, et al. The effect of indoor horseback-riding machine on the balance of the elderly with dementia. J Korean Soc Phys Med. 2008;3(4): 235-46.

Kim EJ. Effects of the physical activities of development impeded children on their social maturity. Docter's Degree. Donga University. 2007.

Kim SY, Youn GH. The relationship between pet dog ownership and perception of loneliness: Mediation effects of physical health and social support. Journal of Institute for Social Sciences. 2014;25(1):215-33.

Kwon JY, Chang HJ, Yi SH, et al. Effect of hippotherapy on gross motor function in children with cerebral palsy: a randomized controlled trial. J Altern Complement Med. 2015;21(1):15-21.

Lee BJ. Effects of participation in an after-school physical activity program on the body composition of students with intellectual disability. KOSAPE. 2007;15(3): 167-81.

Lee CW, Kim SG, Na SS. The effects of hippotherapy and a horse riding simulator on the balance of children with cerebral palsy. J Phys Ther Sci. 2014;26(3):423-5.

Lee CW, Kim SG, Yong MS. Effects of hippotherapy on recovery of gait and balance ability in patients with stroke. J Phys Ther Sci. 2014;26(2):309-11.

Lee HS, Kim EJ. The Effect of The preparation and review times on the some items of the gross motor function measure evaluation capacity of the College Students. J Korean Soc Phys Med. 2015;10(1):99-105.

Lee SG, Jeong JH. The effects of indoor horseback-riding exercise on health-related fitness, serum lipids, and defecation satisfaction of female collegiate students KSR. 2005;16(3): 153-60.

Macauley BL. Neurophysiological foundations of hippotherapy within speech-language pathology. American Hippotherapy Association Preconference workshop. 
Arizona. Phoenix. 2003.

Moraes AG, Copetti F, Angelo VR, et al. The effects of hippotherapy on postural balance and functional ability in children with cerebral palsy. J Phys Ther Sci. 2016;28(8):2220-6.

Mossberg KA. Reliability of a timed walk test in persons with acquired brain injury. J Phys Med Rehabil. 2003;82(5):385-90.

O'Haire ME. Animal-assisted intervention for autism spectrum disorder: A systematic literature review. J Autism Dev Disord. 2013;1-17.

Podsiadlo D, Richardson S. The timed "Up \& Go": a test of basic functional mobility for frail elderly persons. J Am Geriatr Soc. 1991;39(2):142-8.

Ro HL. The Bobath Approach for Walking Improvement on Child with Mental Retardation. J Korean Soc Phys Med. 2008;3(2):113-9.

Schalock RL, Luckasson RA, Shogren KA. The renaming of mental retardation: Understanding the change to the term intellectual disability. Intellect Dev Disabil. 2007;45(2):116-24.

Seo KO. The effects of animal assisted therapy program using therapy dog for the hyperactivity of children with ADHD. Master's Degree. Wonkwang University. 2012.

Shurtleff TL, Standeven JW, Engsberg JR. Changes in dynamic trunk/head stability and functional reach after hippotherapy. Arch Phys Med Rehabil. 2009;90(7): 1185-95.

Song $\mathrm{CH}$. The effects of horse riding therapy Program on depression and sociality of exceptional children. Master's Degree. Kwangwoon University. 2008.

Wehmeyer M, Schwartz M. Self-determination and positive adult outcomes: A follow-up study of youth with mental retardation or learning disabilities. Except Child. 1997;63(2):245-55.

Yoon ST, Park BH. The impact horse riding exercise program has on adults with intellectual disability in physical, psychology factors, social factors of disabled. KOSAPE. 2013;21(1):81-95.

Yoon IJ, Park JE, Song MS, et al. Interrater reliability of Korea child version of the mini-mental statute examination (MMSE-KC). The journal of Korean Society of Cognitive Rehabilitation. 2016;5(2):5-16. 